\title{
Prospective audit of the pattern, severity and circumstances of injury sustained by vehicle occupants as a result of road traffic accidents
}

\author{
A. BRADBURY, \& C. ROBERTSON \\ Department of Accident and Emergency Medicine, The Royal Infirmary, Edinburgh
}

\section{SUMMARY}

The pattern and severity of injuries sustained by 174 vehicle occupants consecutively admitted to the Accident and Emergency Department of the Edinburgh Royal Infirmary were prospectively documented. Drivers (DR) accounted for $66 \%$ of the patients, $20 \%$ were front seat passengers (FSP) and $14 \%$ were rear seat passengers (RSP). Injured patients were more likely to be male, young, intoxicated and not wearing a seat-belt. The position of the patient within the vehicle at the time of the accident and point of impact significantly affected the pattern of injury sustained. The majority of injuries were sustained by the upper body and the pattern of injury is discussed. Most accidents occurred at low speeds and higher speeds were associated with an increased severity of injury. Seat-belts reduced the overall severity of injuries, in particular those to the face and chest, but may increase the risk of neck injury. Head-rests do not appear to influence the incidence of neck injury. Clinically apparent alcohol intoxication was associated with a markedly increased risk of severe injury.

\section{INTRODUCTION}

In the U.K. over 3500 men and 1500 women are killed in road traffic accidents (RTAs) annually (WHO Mortality Statistics 1988). Such figures are all the more tragic when it is remembered that much of this morbidity and mortality is sustained by young and otherwise healthy individuals (Williams \& Carsten, 1989). In addition to the enormous social and economic losses, RTA-related injury places a major burden upon the A\&E, hospital and rehabilitation services. 
Attempts to reduce the frequency of RTA-related injury have only been partially⿳亠口冋! successful. Although U.K. seat-belt legislation is estimated to have saved 500 lives 3 and 19000 non-fatal injuries per year since their introduction in 1983 (Hayes, $\stackrel{\circ}{\circ}$ 1988), compliance remains far from universal and there are important deficiencies $\vec{s}$ in the law. Drinking and driving legislation has also reduced alcohol-relatedof deaths in vehicle users (Transport and Road Research Laboratories, 1977), but enforcement is difficult and incomplete. In addition, the apparent 'softening' of $\frac{\overline{\bar{c}}}{\stackrel{5}{5}}$ police attitudes to speeding (West, 1988) means that the number of RTA-related $\overparen{\Phi}$ deaths and injuries can be expected to remain unacceptably high. is

The aim of this study was to audit prospectively the severity and nature of injury. sustained by vehicle occupants presenting to a busy city-centre A\&E department. $\overrightarrow{\vec{\omega}}$ By careful recording of the circumstances of the accident it was hoped that risk $\stackrel{\omega}{\omega}$ factors for serious injury could be identified. Recognition of these factors would $\stackrel{\Phi}{\mathrm{\Phi}}$. then allow the pattern and severity of injuries to be anticipated making initial ${ }_{-}$. assessment of the injured patient quicker and more accurate.

\section{MATERIALS AND METHODS}

The circumstances, pattern and severity of injuries sustained by 174 private vehicle $\vec{\bullet}$ occupants consecutively admitted to the A\&E Department of the Royal Infirmaby of Edinburgh as a result of RTAs were prospectively documented. The Departmento serves a population of approximately 700000 people although children under thes age of 13 are not routinely seen. Patients transferred from other hospitals wereo excluded from the study.

Patient details including the time of admission and date of birth were recorded $\stackrel{\mathbb{Q}}{\vec{P}}$ by clerical staff. The attending doctor then completed a form detailing the circum-을 stances of the accident, the nature of the injuries sustained and the final disposal. Doctors were also asked to assess whether the patient was under the influence of alcohol at the time of presentation. This judgement was based upon clinical $\stackrel{\$}{3}$ impression, supported where possible by breath alcometer readings. Patients: with breath alcometer readings greater than $80 \mathrm{mg}$ per cent were assumed to be $\stackrel{3}{\text {. }}$. under the influence of alcohol. Patients who could not be categorized in this wayo due either to the severity or nature of their injuries were presumed not to be 2 under the influence of alcohol. Details of the accident such as point of impact, 9 estimated speed and the presence of seat-belt and headrests were gathered by questioning the patients and the attending emergency service personnel.

During the course of this study over 20 doctors, ranging from senior house $N$ officer (SHO) to consultant, attended the patients and recorded details. The notes 0 and radiologist's X-ray reports of all patients were reviewed later and only those $\mathcal{N}^{N}$ fractures demonstrated radiographically were included.

For the purposes of this study the pattern of injury was documented by dividing the body into 10 body regions. Thoracic spinal injuries were included with those of the thorax and those of the lumbar spine with the abdomen. The face was defined as that part of the head lying between the hair-line and chin. Dislocations $\overrightarrow{0}$ and fractures of the shoulder and hip joint were included within the limb region. 
In addition, in-patient records and discharge summaries were consulted, so that the severity of injury could also be assessed by means of the Injury Severity Score (ISS) (Abbreviated Injury Score, 1985).

\section{RESULTS}

\section{Patient characteristics}

Of 174 vehicle occupants, $115(66 \%)$ were DR, $35(20 \%)$ were FSP and $24(14 \%)$ were RSP. Of the DR, $85(74 \%)$ were male compared with $16(46 \%)$ of FSP and 14 $(42 \%)$ of RSP. Thus injured drivers were significantly more likely to be male than injured passengers $\left(P<0.002\right.$ by $X^{2}$-test). The ages of different patient groups by sex are shown in Table 1. Overall there is no significant difference between the ages of male ( $n=111$, mean $33.9 \pm$ SD 17.3 years) and female $(n=63$, mean $=32.8 \pm$ SD 17.6 years) patients. There is no significant difference in the ages of DR and FSP but RSP were significantly younger than both $(P<0.03$ by unpaired $t$-test). Male drivers were more likely to be admitted $\left(P=0.04\right.$ by $X^{2}$-test) than female drivers. Table 1 also shows the distribution of age in each of the three patient categories.

\section{Point and speed of impact}

Tables 2 and 3 show the estimated point and speed of impact in each patient category and the relationship to ISS. DR and FSP were significantly more likely to

Table 1. Age of vehicle occupants

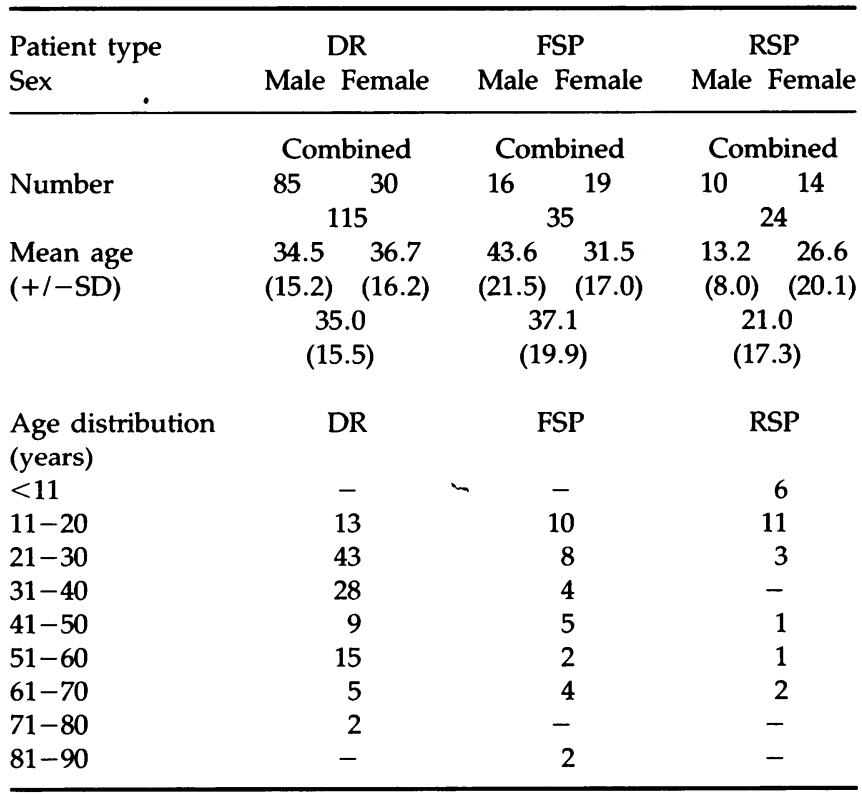


Table 2. Estimated speed of impact

\begin{tabular}{lccc}
\hline Speed (mph) & \multicolumn{3}{c}{ Number of patients/median ISS } \\
\hline & DR & FSP & RSP \\
don't know & $17 / 7$ & $3 / 6$ & $1 / 5$ \\
10 & $6 / 2$ & - & - \\
20 & $23 / 2$ & $6 / 1$ & $7 / 2$ \\
30 & $37 / 3$ & $16 / 1$ & $8 / 2$ \\
40 & $23 / 6$ & $9 / 4$ & $3 / 1$ \\
50 & $8 / 7$ & $1 / 32$ & $1 / 1$ \\
60 & $1 / 1$ & - & $4 / 2$ \\
\hline
\end{tabular}

Table 3. Estimated point of contact.

\begin{tabular}{lccc}
\hline Impact Point & \multicolumn{3}{c}{ Number of patients/median ISS } \\
\hline & DR & FSP & RSP \\
Front & $63 / 5$ & $18 / 3$ & $7 / 3$ \\
Right side & $20 / 5$ & $5 / 9$ & $5 / 2$ \\
Left side & $9 / 5$ & $8 / 2$ & $6 / 2$ \\
Rear & $14 / 1$ & $2 / 1$ & $5 / 1$ \\
Overturned & $9 / 3$ & $2 / 1$ & $1 / 1$ \\
\hline
\end{tabular}

be injured by a head-on impact than RSP ( $P<0.05$ by $X^{2}$-test). Although FSP wereo significantly more likely to be injured in left-sided impacts $\left(P=0.03\right.$ by $X^{2}$-test), $\frac{0}{\circ}$ DR were not at increased risk of injury from right-sided impacts and RSP were not at increased risk from rear impact. However, whereas overall only $29 \%$ of the DR group sustained a neck injury this rose to $71 \%(10 / 14)$ if the impact was from the rear $\left(P<0.001\right.$ by $X^{2}$-test). The median speed of impact was $30 \mathrm{mph}$ for allo three patient groups. However, in each group there were a number of patients $\mathbb{D}$ who were unable (either through injury or through unsighted impact) or unwilling to make an estimate of their speed. There were more 'don't knows' in the DR group than in either the FSP or RSP groups and overall these patients had a higher: ISS. The majority of incidents appeared to occur at low speeds $(20-30 \mathrm{mph})$ in urban areas. There was a tendency for severity of injury (ISS) to increase with the의 patient estimated speed at the time of the accident.

\section{Head-rests, seat-belts and alcohol}

Table 4 shows the proportion of each group wearing seat-belts, having head rest ț support and presenting under the influence of alcohol. Almost a fifth of DR ando FSR and the great majority of RSP were not wearing a seat-belt at the time of the accident. The median ISS of drivers wearing a seat-belt was three compared with nine for those not wearing a seat-belt and thus unbelted patients sustained significantly more serious injuries $(P=0.006$ by Wilcoxon rank sum test). The only FSP with an ISS greater than 25 was not wearing a seat-belt. Although RSP were 
Table 4. Seat-belts, head rests and alcohol.

\begin{tabular}{lccl}
\hline & DR & FSP & RSP \\
\hline Wearing seat-belt & $94(82 \%)$ & $28(80 \%)$ & $2(8 \%)$ \\
Head-rest & $79(69 \%)$ & $20(57 \%)$ & $3(12 \%)$ \\
Alcohol & $9(8 \%)$ & - & $1(4 \%)$ \\
\hline
\end{tabular}

significantly less likely to have head-rests or seat-belts than either DR or FSP $\left(P<0.0001\right.$ by $X^{2}$-test $)$ they did not have significantly more severe injuries.

All of the nine drivers considered to be under the influence of alcohol were male and were significantly younger $(n=9$, mean $25.3 \pm$ SD 6.7 years) than those drivers who were not $(n=106$, mean $=35.2 \pm$ SD 15.3 years $)(P=0.04$ by unpaired $t$-test). The median ISS of drivers under the influence of alcohol was 12 compared with 4 for those drivers that were not and intoxicated drivers were significantly more severely injured $(P<0.005$ by Wilcoxon rank sum test). Intoxicated DR were also significantly more likely to be admitted $\left(P=0.005\right.$ by $X^{2}$-test).

\section{Time of presentation to hospital}

Table 5 shows the distribution of time of presentation to the department for each patient category. There is no statistically significant difference between the three patient groups. However, DR admitted in the 'social hours' of 21.00 to $05.59 \mathrm{~h}$ were almost exclusively male (33 of 34 patients), were more likely not to be wearing a seat-belt $\left(P=0.0004\right.$ by $X^{2}$-test $)$ and to be under the influence of alcohol $(P=0.0001$ by $X^{2}$-test).

\section{Severity of injury}

Table 6 shows the distribution of ISS for each patient group. The majority of injuries in each group were minor and although there are more severe injuries in the DR group than in the other two groups, this did not attain statistical significance. However, of the 11 patients in the study with an ISS greater than 10; nine were drivers of whom five were under the influence of alcohol and three of whom could not be assessed for alcohol due to the severity of their injury. Neither of the FSP with ISS greater than 10 were intoxicated with alcohol although one was a passenger in a car with a injured driver felt to be under the influence of alcohol. Eight of these more severely injured patients (ISS $>10$ ) were not wearing seat-belts.

\section{Pattern of injury}

Table 7 shows the distribution of injuries within each patient group and Table 8 shows the effect of seat-belts on the pattern of injury. The majority of the injuries were to the upper parts of the body with the head, face, neck and thorax sustaining $72 \%$ of all injuries. Neck and thoracic injuries are significantly more common in DR and FSP than in RSP $\left(P=0.03\right.$ and $P=0.035$ respectively by $X^{2}$-test). Although 
Table 5. Time of presentation to hospital

\begin{tabular}{lrcc}
\hline Time $(24$ h clock $)$ & DR & FSR & RSP \\
$00.00-02.59$ & 13 & 1 & - \\
$03.00-05.59$ & 6 & - & - \\
$06.00-08.59$ & 11 & 3 & 4 \\
$09.00-11.59$ & 31 & 10 & 4 \\
$12.00-14.59$ & 2 & 2 & 2 \\
$15.00-17.59$ & 14 & 5 & 3 \\
$18.00-20.59$ & 23 & 10 & 9 \\
$21.00-23.59$ & 15 & 4 & 2 \\
\hline
\end{tabular}

Table 6. Severity of injury

\begin{tabular}{lrrr}
\hline & \multicolumn{3}{c}{ Number of patients score } \\
Injury severity & DR & FSP & RSP \\
\hline $0-5$ & 97 & 31 & 22 \\
$6-10$ & 9 & 2 & 2 \\
$11-20$ & 6 & 1 & - \\
$21-30$ & 3 & 1 & - \\
\hline
\end{tabular}

Table 7. Pattern of injury

\begin{tabular}{lrrr}
\hline & & \multicolumn{2}{c}{ Number of patients (\%) } \\
Body region & DR & FSP & RSP \\
\hline Head & $30(26)$ & $7(20)$ & $2(8)$ \\
Face & $33(29)$ & $10(29)$ & $10(42)$ \\
Neck & $33(29)$ & $8(23)$ & $1(4)$ \\
Thorax & $40(35)$ & $16(46)$ & $3(12)$ \\
Adbomen & $6(5)$ & $1(3)$ & $1(4)$ \\
Pelvis & $7(9)$ & $1(3)$ & 1 \\
R. Arm & $10(11)$ & $6(17)$ & $2(8)$ \\
L. Arm & $5(4)$ & $3(9)$ & $3(12)$ \\
R. Leg & $20(17)$ & $6(17)$ & $4(17)$ \\
L. Leg & $5(4)$ & $3(9)$ & $2(8)$ \\
\hline
\end{tabular}

Table 8. Effect of seat-belts on head facial and neck injuries

\begin{tabular}{llccccc}
\hline Patient & Wearing & \multicolumn{4}{c}{ Number of patients with injury } \\
Group & seat-belt & Face & Head & Neck & Thorax \\
\hline DR & Yes (94) & 23 & 23 & 32 & 28 \\
& No & $(21)$ & 10 & 7 & 1 & 12 \\
FSP & Yes (28) & 7 & 3 & 7 & 14 \\
& No & $(7)$ & 3 & 4 & 1 & 2 \\
RSP & Yes & $(2)$ & - & - & 1 & - \\
& No (22) & 10 & 2 & - & 3 \\
Total & Yes (124) & $30(24 \%)$ & $26(21 \%)$ & $40(32 \%)$ & $42(34 \%)$ \\
& No (50) & $23(46 \%)$ & $13(26 \%)$ & $2(4 \%)$ & $17(34 \%)$ \\
\hline
\end{tabular}


facial injuries are more common in the RSP group althought this did not attain statistical significance. In general facial injuries were significantly $(P<0.008$ by $X^{2}$-test) associated with not wearing a seat-belt whereas wearing a seat-belt was significantly associated with an increase in neck injuries $\left(P=0.00018\right.$ by $X^{2}$-test). Seat-belt wearing did not significantly affect the risk of sustaining a head injury outwith the facial area but did protect DR $\left(P=0.03\right.$ by $X^{2}$-test) and RSP, but not FSP from thoracic injury. Of the 42 patients sustaining neck injuries only 12 did not have a head-rest and within the DR group 25/79 (32\%) patients with head-rest suffered a neck injury compared with $8 / 36$ (22\%) that did not have a head-rest. Although far fewer RSP had headrests they appeared less likely to sustain a neck injury $(1 / 24)$ than either DR $(33 / 115)$ or FSP $(8 / 35)$. Injuries to the right arm and leg were more than twice as common as injuries to the left. Drivers were injured in 1.64 body areas per patient compared with 1.74 for FSP and 1.21 for RSP.

\section{DISCUSSION}

During the period of the study 13434 patients were admitted to the A\&E Department of the Royal Infirmary of which $380(2.8 \%)$ presented with injuries resulting from RTAs. The 174 injured vehicle occupants described in this study therefore represent $1.3 \%$ of the workload of the department and $46 \%$ of the injuries attributable to RTAs.

Two-thirds of the patients were drivers with $20 \%$ being FSP and only $14 \%$ RSP. This may simply reflect the relative use of vehicles by single persons and groups. Alternatively, one might speculate that for some reason being a driver is inherently more dangerous than being a passenger. Drivers admitted to the department appeared to have more severe injuries than passengers. In addition, drivers were more likely than passengers to be male and male drivers were also more likely to be admitted. Interestingly, Evans (1988) found that FSP were more likely to be female and that females were more likely to be injured than males. Injured RSP were younger than DR and FSP and comprised a large proportion of patients under 17 years old. The majority of injured drivers were in the 21-30 age group whereas in the RSP group half the patients were less than 17 years old. It is encouraging to note that none of the injured drivers were below the legal age to drive and that none of the FSP were under 14 years old. However, it is disappointing that none of the three injured infants riding as RSP were in child-restraints. However, because the department does not routinely admit patients under 13 years, the study almost certainly under-estimates the injuries to children arising from RTAs in the area.

Although estimation of the point of contact was possible for all patients, either through direct questioning of the patient or emergency personnel, the accuracy of the information is unknown. Nevertheless, the impact point was found to significantly influence the pattern and severity of injury. DR and FSP were particularly at risk from front-on impact and, although passengers were at increased risk from left-sided impacts, DR were not at risk from right-sided impact. RSP, although mostly without the benefit of seat-belts, do not appear to be at increased risk of injury from rear impact and indeed the rear appeared to be relatively safe (Evans \& Frick, 1988). Overall $12(7 \%)$ patients were injured in vehicles that 
overturned. Nine of these patients were drivers and tended to be travelling high speed. Rear impact was significantly associated with an increased risk of neck injury. Head-rests did not appear to reduce the incidence of neck injury sథ confirming the work of others (Porter, 1989).

One can easily imagine that a patient's assessment of speed might be poor for 형 number of reasons. For example, in 21 cases (17 of them DR) no estimate of the speed was possible either to due inability or unwillingness on the part of the patient. Perhaps not surprisingly such 'don't knows' had more serious injuries $\mathbb{\Phi}$ Nevertheless, there is a good correlation between estimated speed and severity of injury, suggesting that inquiring about the speed of the impact is a useful exercise $\overrightarrow{0}$

Disappointingly, almost a fifth of DR and FSP and the great majority of RSE (Bodiwala et al., 1989) were not wearing a seat-belt at the time of the accident an this was strongly associated with an increased risk of severe injury. In particular seat-belts reduced the incidence of facial injuries but did not affect head injuries. outwith the facial area. By contrast, there was a small increase in the incidence of minor neck injuries in those wearing a seat-belt (Perkins \& Layton 1988, Porte $\dot{G}$ 1989). Interestingly, seat-belts significantly reduced the incidence of thoracie injury in DR but not in passengers. Furthermore, thoracic injuries in non-wearers were markedly more severe than those of wearers who usually sustained abrasion and bruises from the belt itself.

The separation of patients into those thought to be and those thought not to be under the influence of alcohol was based on the clinical impression of \$⿸\zh14𠃋 attending doctor supported where possible by breath alcohol measuremen This approach has previously been used with success with regard to the stute of injured pedestrians (Bradbury, 1991) and there appears to be close correlation between blood and breath alcohol estimations (Gerberich et al., 1989). The measure $\frac{0}{\mathbb{D}}$ ment of blood alcohol levels is impractical in routine practice and may be refuse $\mathbb{\&}$ by the patient. There is also general agreement that back interpretation of bloo $\vec{\Phi}$ alcohol levels is both difficult and potentially misleading (Lewis, 1988). Nine drivers were judged to be under the influence of alcohol at the time of presentation? In a number of other cases this assessment could not be made, and in these cases alcohol was assumed not to be involved. All the alcohol affected drivers were male, were significantly younger than other male drivers, were more likely to be admitted and were more severely injured. These results clearly refute anecdotad reports that drunk drivers escape RTA without serious injury (Kirn, 1988).

The majority of patients were admitted through the busy morning and evening rush-hour periods. However, drivers admitted during the 'social hours' between 21.00 and $03.00 \mathrm{~h}$ were markedly different in that they were more likely to be male to be under the influence of alcohol and not to be wearing a seat-belt.

In conclusion, this prospective audit of 174 vehicle occupants injured as a resulf of RTAs has demonstrated that such injuries comprise a significant proportion ot the workload of the department. Fortunately, the majority of the injuries sustaine were minor. However, the majority of severely injured patients were young, male intoxicated, unbelted drivers who were admitted in the late evening/earl morning. The study also demonstrates the importance of gaining as much informa tion as possible about the patient and mechanism of collision, in assessing the likely pattern and severity of injury. 


\section{ACKNOWLEDGEMENTS}

I should like to thank Dr K. Little and Dr C. Robertson, Consultants in Accident and Emergency Medicine for allowing me to study their patients and all of my colleagues for their participation the study.

\section{REFERENCES}

Abbreviated Injury Scoring, 1985 Revision, Committee on Injury Scaling, American College of Surgeons (1985).

Bodiwala G. G., Thomas P. D. \& Otubushin A. (1989) Protective effect of rear-seat restraints during car collisions. Lancet i, 369-371.

Bradbury A. W. (1991) Pattern and severity of injury sustained by pedestrians with particular reference to the effect of alcohol. Injury 22, 132-134.

Evans L. (1988) Risk of fatality from physical trauma. Journal of Trauma 28, 368-378.

Evans L. \& Frick M. C. (1988) Seating position in cars and fatality risk. American Journal of Public Health 78, $1456-1458$.

Gerberich S. G., Gerberich B. K., Fife D., Cicero J. J., Lilia G. P., Van Berkom L. C. (1989) Analysis of the relationship between blood alcohol and nasal breath alcohol concentrations: implications for assessment of trauma cases. Journal of Trauma 29, 338-343.

Hayes H. R. M. (1988) Seat belt laws: the United Kingdom experience. Bulletin of the Nez' York Academy of Science' 84, 721-727.

Kirn J. F. (1988) Debunking the drunk-driver-and-survival myth. Journal of the American Medical Association 260, 2480.

Lewis K. O. (1988) Back calculation of blood alcohol. British Medical Journal 295, 800.

Perkins C. S. \& Layton S. A. (1988) The aetiology of maxillo-facial injuries and the seat belt law. British Journal of Maxillofacial Surgery 26, 353-363.

Porter K. M. (1989) Neck sprains after car accidents. British Medical Journal 298, 973-974.

Transport and Road Research Laboratories, Alcohol and Road Accidents: Blood Alcohol Levels. Leaflet 634, 1977, Crewthorne, Berkshire.

West R. (1988) Slowing the speedy. British Medical Journal 297, 1069-1070.

WHO Mortality Statistics Annual Report (1988) WHO, Geneva.

Williams A. F. \& Carsten O. (1989) Driver age and crash involvement. Anterican Journal of Public Health 79, 326-327. 